\title{
A Comparative Analysis of Three Translation Versions of The Old Man and the Sea from the Perspective of Domestication and Foreignization
}

\author{
Xian Zhong ${ }^{1}$ \\ ${ }^{1}$ International Office, Taishan College of Science and Technology, Taian, Shandong 271038, China \\ *Corresponding author. Email:85358682@qq.com
}

\begin{abstract}
As Hemingway's last work, The Old Man and the Sea won him the Pulitzer Prize and the Nobel Prize in literature, and established his prominent position in world literature. There are currently more than 300 translation versions of Hemingway's classic The Old Man and the Sea in China. This article explores the translation of terms and language styles in different eras based on three Chinese versions translated by Zhang Ailing, Wu Lao and Sun Zhili, and finds that Zhang's version is domestication-oriented, Sun's version is foreignization-oriented and Wu's version is in-between. Then this article analyzes the influence of the development of the ages on the translation of The Old Man and the Sea, and states that translation strategies of classic retranslation change from domestication to foreignization with the time change.
\end{abstract}

Keywords: The Old Man and the Sea, comparative analysis, domestication, foreignization

\section{INTRODUCTION}

As Hemingway's last work, The Old Man and the Sea won him the Pulitzer Prize and the Nobel Prize in Literature, and established Hemingway's prominent position in world literature. Hemingway regarded it as the best work he could write in his life. The work showed the protagonist Santiago's graceful demeanor and undefeated spirit under heavy pressure, and created the most famous tough guy image in the history of literature which has inspired generations of readers. From the perspective of stylistic style, the work is short and concise, with a total of 26,640 words in the full text, with an average sentence length of about 14.7 words. It uses more short and powerful sentence patterns, showing the author's telegram style, which is his distinctive style characteristics. At the same time, the work embodies the principle of "iceberg" used in Hemingway's writing, and uses the most concise and solemn method to depict images with profound meaning, so as to arouse the imagination of readers to dig out the "seven-eighths" of the iceberg hidden underwater.

The Old Man and the Sea has been widely praised since its publication in 1952. Since Zhang Ailing published the first Chinese translation in 1955, the work has been retranslated more than 300 times in 66 years.
Due to the influence of the patron, the style of the translator, and the factors of the times, different translations have different styles. From the time of its first translation and introduction, to the period of the establishment of diplomatic relations between China and the United States during the reform and opening up of China, and then to the 21 st century, this article selects three Chinese versions translated by Zhang Ailing, who first translated and introduced The Old Man and the Sea, Wu Lao, who is known as an expert on the study of Hemingway, and Sun Zhili, who is a famous translation theorist. And the terminology and style of the three translations are analyzed from the perspective of domestication and foreignization.

\section{LITERATURE REVIEW}

\subsection{Translation strategies of domestication and foreignization in China}

In 1955, inspired by Schleiermacher, Lawrence Venuti first put forward domestication and foreignization in The Translator's Invisibility: A History of Translation. In his book, a domesticating method refers to an ethnocentric reduction of the foreign text to target-language cultural values, bringing the author back 
home, and a foreignizing method refers to an ethnodeviant pressure on those values to register the linguistic and cultural difference of the foreign text, sending the reader abroad ${ }^{[1]}$. Those two translation strategies are similar to the literal translation and free translation, which has been debated in the field of Chinese translation for thousands of years. In the early days of the founding of the People's Republic of China, Mao Dun published "Struggling for the Development of Literary Translation and Improving the Quality of Translation" at the National Literary Translation Conference in 1954. He proposed the theory of "artistically creative translation" and pointed out that the core issue of translation was artistry. Translators of foreignization-oriented should recognize that translation needs to "grow on our soil and water". Translators such as Qian Zhongshu and Fu Lei held the same view. Qian Zhongshu believed that a book should be so faithful to the original work that it does not read like the translated version, because the work will never read like the translated text in the original text. In 1955, the "Wenhui Book Weekly" and the Translation Research Center of the Department of Western Languages of Nanjing University conducted a large translation debate, and investigated several translations of The Red and the Black. From the 1980s to the beginning of this century, there was a rethinking of domestication and foreignization again. In 1996, Sun Zhili published "Adhere to Dialectics and Establish a Correct View of Translation", referring to Fu Lei's view of "emphasis on the spirit but not the form". "Because of overemphasizing the opposition of contradictions and ignoring the unity of contradictions, it is easy to mislead young translators, causing a tendency to emphasize the spirit over the form." ${ }^{[2]}$

\subsection{Research on the translation of The Old Man and the Sea}

According to incomplete statistics, since the publication of the first translation in 1955, there have been more than 300 existing Chinese versions of The Old Man and the Sea. Among them, from the perspective of translation and introduction, they are mainly divided into children's literature and classic literature; from the perspective of the completeness of the translated version, they are mainly divided into two forms: the compiled version and the fully translated version. This article selects three translations translated by Zhang Ailing (1955), who first translated the work, Wu Lao (1980), who is known as an expert on the study of Hemingway, and Sun Zhili (2010), a contemporary translation theorist, to conduct a research. The time span of the three translators is more than half a century, spanning across the Taiwan Strait in space, with different social statuses, cultural backgrounds and historical environments, and they are all highly representative in the specific time period. The author mainly searches on CNKI using The Old Man and the Sea and "translation" as key words to study the research status of the translation of The Old Man and the Sea in China.

From the perspective of the translators, there are 50, 6 and 2 papers on the translations of Zhang Ailing, Wu Lao, and Sun Zhili respectively. There are a lot of articles related to Zhang Ailing, mainly from the characteristics of the translator, the subjectivity of the translator, the translation style, the translation of culture-loaded words, feminism, and translation skills. For example, taking The Old Man and the Sea as the subject for research, Yang Ruizhi has made an attempt to make a delicate contrastive study on the three Chinese versions, from the perspective of feminist translation theory, in the hope of finding out which feminist intervention strategies have been adopted for the translation of that work, and that how Zhang Ailing has fulfilled her translation ideal through the application of feminist intervention strategies ${ }^{[3]}$. Researches on $\mathrm{Wu}$ Lao's translation are mainly carried out from translation style, translation strategy, and culture-loaded words translation. For example, Wei Jiangshuai combed out the differences in linguistic typology and philosophical aesthetics of hypotaxis and parataxis to analyze $\mathrm{Wu}$ Lao's unique style, and analyzed Wu Lao's translation of The Old Man and the Sea from the perspectives of lexical, syntactic and textual levels, hoping to derive corresponding literary translation strategies to guide translation practice ${ }^{[4]}$. There are only two articles related to Sun Zhili comprising his translation perceptions and interviews respectively, to discuss translation styles and issues involved in literary translation. For example, Sun Zhili combined his own experience in translating The Old Man and the Sea to illustrate with examples that the style of the translation should be that of the author, and the translator should not change it at well ${ }^{[5]}$.

From the perspective of comparison of translations, 13 articles are compared from different perspectives of translators. There are 12 papers to study the comparison of multiple translators. For example, under the framework of aesthetics of reception, Shi Tiantian selected 40 pieces sample texts from the two versions with obvious differences, and analyzed them in detail from the following three aspects: horizon of expectation, indeterminacies and gap, and appealing structures ${ }^{[6]}$. There is one article that studies the same translator's version in different periods. That is, Jia Xin drew on the theories and methods of literary sociology to compare two versions, and found subtle changes in translation techniques and language styles, trying to grasp the changes of the times and society in China for more than 50 years ${ }^{[7]}$.

From the perspective of the application of translation theory, there are 21 articles that have been researched from the labeling theory, ecological translation theory, 
rewriting theory, translation adaptation and selection theory, functional equivalence, and relevance translation theory. For example, Chang Qing combined the "selective adaptation" of the original text by well-known translators on both sides of the Taiwan Strait in different periods, integrated cultural connotation, communicative intentions, language ecology, psychological cues, aesthetic pursuits and other dimensions to evaluate the effect of text transplantation of retranslation, and referred to the quality of translators and reader feedback to comprehensively evaluate the degree of integration and adaptation of the translated version ${ }^{[8]}$.

Therefore, translation studies mainly focus on the horizontal studies of different translations, and there are few longitudinal studies of different translations. This article selects the translations of three representative translators in three important time periods since the founding of the People's Republic of China, and studies the impact of the changes of the times and the law of change on the terminology and style of translations from the perspective of domestication and foreignization.

\section{A COMPARATIVE STUDY OF THE THREE TRANSLATIONS}

\subsection{Translation of terminology}

In The Old Man and the Sea, the author integrates multi-level meanings into a simple story. In order to achieve this goal, the work involves a large number of distinctive terms, including appellations, Spanish words, and culture-loaded words. However, different translators adopted different translation methods and presentation forms of the above terms.

\subsubsection{Translation of appellation words}

The appellation of the protagonist in The Old Man and the Sea appeared 228 times, presented in two forms: "the old man" (201 times) and "old man" (27 times), wherein "the old man" is used by the author to refer to the protagonist, and "old man" is used to describe the protagonist by other people in the work, including the boy and the protagonist himself. The author uses "the old man" to refer to the protagonist without calling his name, which represents the unique image of the protagonist in the author's mind and reflects the author's admiration for the protagonist and is accordance to the translation of the title. "Old man" is used to distinguish the appellation of the protagonist by the author and other people in the work.

Zhang Ailing has achieved the unity of terminology translation when translating the protagonist's appellation, and literally translated the author's appellation to the protagonist "the old man" as "老人". The appellation of other characters in the text "old man" was translated into "老头子", and the translation was translated using domestication. For example, the boy calls the protagonist "old man". In Chinese culture, people pay attention to respect for seniority. Young boys should use polite language to older people. However, in Chinese dialects, "old man" can be used for sons calling fathers, people calling older men, or wives calling older husbands. Therefore, this translation reflects the profound friendship between the boy and the protagonist.

Similar to Zhang Ailing's translation, Wu Lao also literally translated the author's appellation of the protagonist "the old man" as "老人". However, when translating "old man", he adopted flexible translation according to different contexts, such as “老大爷”, “老家 伙” and “老头儿”.

When Sun Zhili translated the appellation of the protagonist, he distinguished the appellation of different characters and achieved a unified style of terminology translation. Sun Zhili unified and literally translated the author's appellation of the protagonist "the old man" into "老人", which was consistent with the translation of the title. When translating "old man", he used flexibly translation method. The boy addressed him as "老人家", reflecting the boy's respect for the older protagonist; and the protagonist called himself "老家伙". The appellation words are more in line with the cognitive context of the target readers.

Table 1 Word frequency of the appellation of the protagonist "the old man" and "old man" translated by Zhang Ailing,

Wu Lao and Sun Zhili

\begin{tabular}{|c|c|c|c|c|c|c|c|c|c|}
\hline Translators & \multicolumn{2}{|c|}{ Zhang Ailing } & \multicolumn{4}{c|}{ Wu Lao } & \multicolumn{3}{c|}{ Sun Zhili } \\
\hline Translations & 老人 & 老头子 & 老人 & 老大爷 & 老家伙 & 老头儿 & 老人 & 老人家 & 老家伙 \\
\hline $\begin{array}{c}\text { Word } \\
\text { frequency }\end{array}$ & 214 & 26 & 214 & 8 & 8 & 10 & 227 & 8 & 12 \\
\hline
\end{tabular}

\subsubsection{Translation of Spanish words}

There are 23 loan words in The Old Man and the Sea, all in Spanish, mainly including modal words and various names (ocean, place, team, shark, etc.). Spanish is directly introduced into the work for two reasons. On the one hand, Spanish words have gender difference, while English words do not have this attribute. The author can more accurately express the protagonist's complex feelings through the choice of words; on the 
other hand, due to the fact that the protagonist's prototype is a Cuban. The story took place near the Cuban capital. The introduction of Spanish added the exotic color to the work and makes the story more authentic.

Zhang Ailing, Wu Lao and Sun Zhili selected quite different translation strategies in Spanish words translation. When Zhang Ailing dealt with Spanish words, except for the deletion of two whole sentences, the other parts were translated into Chinese by domestication. Although this practice broke through readers' reading barriers, it also led readers not to experience the author's writing technique of defamiliarization. From the perspective of modal words translation, Zhang Ailing adopted domestication strategies, such as translating Spanish "Ay" into "唉". From the perspective of the translation of the names, Zhang Ailing adopted domestication strategies, using the methods of flexible translation, generalization, and explanatory translation, except for the deletion of two whole sentences without translation. For example, she translated "salao" into "晦气星"; "guano" into "一种棕 树"; "la mar" into "海娘子" and so on.

When Wu Lao translated Spanish words, he adopted both domestication and foreignization strategies. When translating modal words, $\mathrm{Wu}$ Lao used the foreignization strategy. As an expert on the study of Hemingway, he consulted Hemingway's description of the Spanish "Ay": This word cannot be translated. Maybe it's just a shout, like a person felt a nail passing through his hands and knocking them into the wood to give out an involuntary sound", so he retained the word. For the translation of the names, Wu Lao retained the original text and annotated the words with Spanish unique features. For example, Spanish has two parts of speech, feminine and masculine, and neither English nor Chinese has this feature. Therefore, $\mathrm{Wu}$ Lao retained the two words "la mar" and "el mar" to describe the ocean in the original text, and explained the part of speech of these two words in the footnotes. For other Spanish names, domestication strategies were adopted, such as literal translation, transliteration etc. For example, "agua mala " was literally translated as "水母"; the place name "Cienfuegos" is transliterated as "西恩富戈斯" and so on.

When Sun Zhili translated Spanish words, he only used foreignization strategies, and adopted the method of retaining the original text with annotations, so as to keep the foreign cultural flavor of the original text as much as possible. In the translator's preface, Sun Zhili mentioned that the translator should try to embody the defamiliarization of the original text. He believes that Hemingway's novels are written in English, and the readers are naturally English readers. However, the old man described in the novel is a Cuban and he speaks Spanish. The author inserted about 20 Spanish words in the book, not only to highlight the identity and background of the elderly, but also to stimulate interest and beauty through defamiliarization. Therefore, in order to respect the original text, Sun Zhili retained Spanish as much as possible and added footnotes to explain their meanings. For example, Sun Zhili translated the Spanish "salao" by copying the same and adding a footnote. This method not only makes the attributive clause after the word more reasonable in the work, but also conveys the original author's ideographic method.

\subsection{Translation of culture-loaded words}

As one of the 32 landmark books in American history, The Old Man and the Sea condenses Hemingway's personal outlook on the world and life, which inevitably involves American culture-loaded words related to American baseball culture, religious culture etc. As Translation is an important device in intercultural communication, the translator cannot neglect the cultural information embodied in messages. Li Lili and Zhong Xian considered that literary translation is the transformation of cultural information between two language forms, which involves the cultural differences between different nations. If literary translation is only regarded as the transformation of different language expressions, there would be cultural default, cultural mistranslation and other problems, which will affect the quality and effect of literary translation ${ }^{[9]}$. Therefore, in the translation process, translators need to consider the differences between Chinese and American cultures and select appropriate translation strategies to accurately achieve facsimile of culture.

Original: In the other league, between Brooklyn and Philadelphia I must take Brooklyn ${ }^{[10]}$.

Zhang Ailing: 在另外那个联赛里, 在布鲁克林和 费城两队里面, 我还是宁愿要布鲁克林队 [11]。

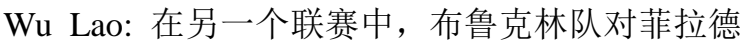
尔菲亚队，我看布鲁克林队准赢。

Footnote: 指另一大联赛，全国联赛。这两大联赛 每年通过比赛选出一个胜队, 于 10 月上半月在双方 的场地轮流比赛, 一决雌雄, 名为“世界大赛” [12]。

(Footnote: It refers to another major league, the National League. The two major leagues select a winning team each year through competitions, and take turns to compete on both sides in the first half of October. A showdown is called the "World Series".)

Sun Zhili: 在另一个联盟中, 布鲁克林队对费城 队, 我看布鲁克林队准赢。

Footnote: 美国有两大职业棒球联盟，一是美国联 盟（American League），一是全国联盟（National 
League）。美国职业棒球联赛分常规赛和季后赛两个 阶段。先由两大联盟各决出一个胜队, 再由两队进行 总决战, 产生两大联盟的最终冠军 ${ }^{[13]}$ 。

(Footnote: There are two major professional baseball leagues in the United States. One is the American League and the other is the National League. The American professional baseball league is divided into two stages: the regular season and the playoffs. The two major leagues decide on a winning team first, and then the two teams have a final battle to produce the final champion of the two major leagues.) (English version's footnotes are translated by the author)

According to the context, "the other league" is an organization related to baseball. American readers can easily understand that it refers to the National League. However, most Chinese readers have rarely been exposed to baseball and have little knowledge of American baseball culture, so it is difficult to respond what kind of baseball organization it is in 1955. Under the circumstances, Zhang Ailing adopted a literal translation, which caused Chinese readers and American readers to have different feelings when reading the work. $\mathrm{Wu}$ Lao and Sun Zhili also chose literal translation, but explained in detail through adding footnotes to better convey the foreign cultural information of the work to its Chinese readers.

\subsection{Translation of diction style}

The style of the translation not only reflects the style of the original author, but also is influenced by the style of the translator to a certain extent. For example, Hemingway's reference to the big fish is not uniform in the text. From the initial "it" to the later "he", it reflects his emotional change towards the big fish: from an ordinary prey to a respectable opponent, friend or even brother. The three translators have different views on this issue.

Original: "It was noon when I hooked him," he said. "And I have never seen him. ${ }^{[10] "}$

Zhang Ailing: “我正午钓到他的, ”老人说。“而我 到现在还一次都没看见过他。[11]”

Wu Lao: “我是中午把它钓上的, ”他说。“可我始 终还没见过它。[12]”

Sun Zhili: “我是中午钓上它的, ”他说。“可我一直 还没看见过它。[13]”

From this sentence, the protagonist has regarded the big fish as his opponent at this time, and Wu Lao and Sun Zhili always translated their reference to the big fish as "it". Therefore, in terms of the diction style, although these two authors achieved a unified terminology, it did not convey the author's intention. However, Zhang Ailing's translation is loyal to the original selected words and accurately interprets the author's emotional changes.

Original: "Half fish," he said. "Fish that you were. I am sorry that I went too far out. I ruined us both. But we have killed many sharks, you and I, and ruined many others ${ }^{[10]}$.

Zhang Ailing: “半条鱼，”他说。“你这“从前是一条 鱼”的东西。我很懊悔我出海太远了。我把我们俩都 毁了。但是我们杀了许多鲨鱼——你同我—鲨鱼不 给我们杀了也给我们毁了 ${ }^{[11]}$ 。

Wu Lao: “半条鱼, ”他说。“你原来是条完整的。 我很抱歉, 我出海太远了。我把你我都毁了。不过我 们杀死了不少临鱼, 你跟我一起, 还打伤了好多条 ${ }^{[12]}$ 。

Sun Zhili: “半拉鱼, ”他说。“你本来是一整条鱼。 很遗憾, 我出海出得太远了。我把我们俩都毁了。可 是我们杀死了不少鲨鱼, 你和我一起, 还打伤了好多 条 ${ }^{[13]}$ 。

The above example shows that Hemingway's language is concise and he likes to use colloquialism. Wu's version and Sun's version are relatively similar, the diction is concise and easy to understand, and the sentence structure is closer to the original text, making the translator's "invisible". However, Zhang's translation is obviously different from the first two. After fully understanding the author's inner activities, Zhang's translation adds unique emotional vocabulary which is more literary.

Zhang Ailing translated "Fish that you were." as "你 这"从前是一条鱼"的东西", and added the structure of "你这......的东西" (“you are such a thing of...") to make the language more colloquial and more emotional. The translations of Wu Lao and Sun Zhili are basically the same, using a concise sentence structure without adding extra words. Similarly, Zhang Ailing translated "and ruined many others" as "鉴鱼不给我们杀了也给 我们毁了". According to the context, Zhang Ailing added the structure of “不给......也给......" ("either... or...") and complemented the first half of the structure by repeating the meaning of the previous sentence. That slightly changes the meaning of the original text, but emphasizes the results of the battle between the old man and the big fish. However, Wu Lao and Sun Zhili's translation of this sentence is exactly the same, and the translation is "还打伤了好多条", which is faithful to the original text and does not strengthen the author's intention.

\section{CONCLUSION}

The change of translation strategy in the process of classic retranslation reflects the country's opening-up level and the diachronic changes of the people's growing cultural needs to a certain extent. This article selects the three translations of Zhang Ailing, Wu Lao 
and Sun Zhili as the corpus, and explores the similarities and differences between terminology translation and the diction style of the translations in different eras from the perspective of domestication and foreignization. From the perspective of terminology translation and diction style, Zhang Ailing's translation tends to be domestication-oriented, Sun Zhili's translation tends to be foreignization-oriented, and Wu Lao's translation is somewhere in between. It can be seen that the translation is not only related to the original author's style, but also influenced by the specific age and the translator's personal style. From the beginning of the reform and opening up of China to the present, the choice of translation strategies for the translation of this work has shown a trend of change from domestication to foreignization.

\section{REFERENCES}

[1] Venuti, Lawrence. The Translator's Invisibility: A History of Translation. New York: Taylor \& Francis e-Library. 2004:19-20.

[2] Sun, Zhili. "Adhere to Dialectics and Establish a Correct View of Translation". Journal of PLA University of Foreign Languages. 1996(05):43-49.

[3] Yang, Ruizhi. "Eileen Chang's Translation of The Old Man and the Sea from a Perspective of Feminist Translation Theory". North University of China, 2011.

[4] Wei, Jiangshuai. "Translation Strategies of Hypotaxis and Parataxis in English and Chinese-Taking Wu Lao's Translation of The Old Man and the Sea as an Example". Overseas English. 2018(19):141-143.

[5] Sun, Zhili. "Everything Follows Original Translation-Impressions on Translating The Old Man and the Sea". Contemporary Foreign Languages Studies. 2012(04):59-62.

[6] Shi, Tiantian. "A Comparative Study of the Two Translated Versions of The Old Man and the Sea from the Perspective of Reception Theory". Xi'an Technological University, 2013.

[7] Jia, Xin et al. "A Comparative Study of Yu Guangzhong's Translation of The Old Man and the Sea of 1957 Edition and 2010 Edition-Language Changes and Social Changes". Hundreds of Prose (New Chinese Loose Leaf). 2018(11):1-2.

[8] Chang, Qing. "Eco-Translation Studies of Literary Retranslation-Taking the Five Chinese Versions of The Old Man and the Sea as Examples". Journal of Ningxia University (Social Science Edition). 2019, 41(06):60-66.

[9] Li Lili \& Zhong Xian, Obstacles and
Countermeasures of English Translation from a Cross-cultural Perspective. Changchun: Jilin Publishing Group Co., Ltd. 2021:93.

[10] Hemingway, Ernest. The Old Man and the Sea. Beijing: China Translation \& Publishing House, 2011:9, 24, 68 .

[11] Hemingway, Ernest. The Old Man and the Sea. Trans. Zhang, Ailing. Beijing: Beijing October Literature and Art Publishing House, 2020:13, 28, 72.

[12] Hemingway, Ernest. The Old Man and the Sea. Trans. Wu, Lao. Shanghai: Shanghai Translation Publishing House, 2010:11, 27, 68.

[13] Hemingway, Ernest. The Old Man and the Sea. Trans. Sun, Zhili. Shanghai: Shanghai Literature and Art Publishing House, 2019:10, 26, 71. 